\title{
Autism Spectrum Disorders
}

\author{
Andreas M. Grabrucker, PhD
}

Editor

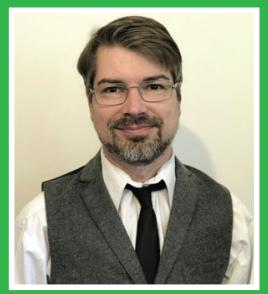

Andreas M. Grabrucker, PhD, is a tenured Associate Professor at the University of Limerick, Ireland, and a member of the Bernal Institute, where he acts as the Lead for the Bio Materials Research Cluster. Dr. Grabrucker is also a member of the Health Research Institute of the University of Limerick. Dr. Grabrucker received his MSc in Biology from the Technical University of Munich, Germany, and his PhD in Molecular Medicine from UIm University, Germany. He continued his research in the United States at Stanford University, Stanford School of Medicine. From 2011 to 2016, he was a tenure-track Assistant Professor and Executive Director of the Neurocenter of UIm University. In 2019, he was awarded a guest professorship at the University of Modena and Reggio Emilia, Italy. His primary research focus is translational neuroscience in autism spectrum disorders. He has generated model systems to understand neurobiological processes of brain development and function and explores the use of nanotechnology for targeted drug delivery into the brain. He has published over 60 peer-reviewed articles and 13 book chapters. He is the author of the book "Eco-Neurobiology and how the environment shapes our brain", and the first textbook detailing the role of "Biometals in Autism Spectrum Disorders."
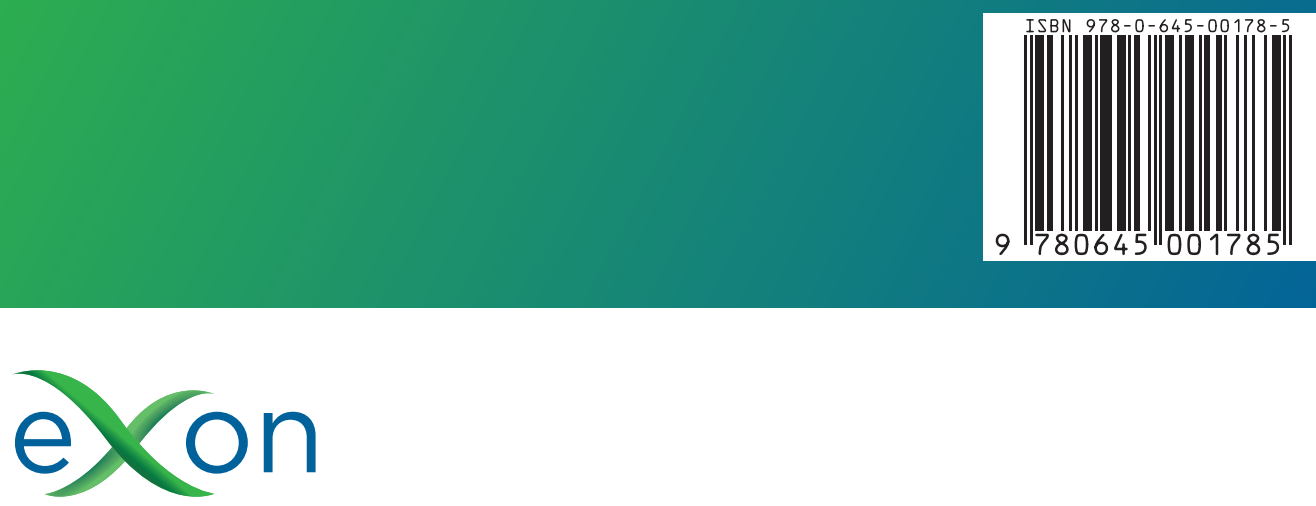

PUBLICATIONS 